\title{
Overcoming Cultural Barriers in Distributed Work Environments
}

\author{
A comprehensive, internet-based concept
}

Ralf Lossack and Matthias Sander

University of Karlsruhe, Institute for Applied Computer Science in Mechanical Engineering (RPK), Kaiserstr. 12, 76131 Karlsmihe, Germany.

Email:\{lossack, sander\}@rpk.uni-karlsruhe.de

\begin{abstract}
This paper presents an approach on how to overcome intercultural barriers in European-Chinese engineering projects via an Internet portal. It is the result of one of the work packages of the EU project DRAGON. In consideration of the main users' requirements and the special preconditions that Chinese-European collaboration implicates, portal functionalities are conceived that support the project participants throughout their intercultural collaboration process.
\end{abstract}

Key words: Distributed product development, Cultural differences, Internet-based support

\section{INTRODUCTION}

One of the main challenges companies face today is the globalisation of business processes. Many companies respond to this challenge by establishing cross-national co-operations. Thus, internal and external partners worldwide are integrated in value chains that aim at benefiting from the local advantages of the specific locations. Recently, this policy has been applied in the field of product development. This study illustrates that many problems in product development between distant located collaboration partners are based on cultural differences. Consequently, adjusting cultural differences is of pivotal importance for the success of these projects.

Within the scope of the European Commission project DRAGON (Development of an inteRActive EnGineering Portal for Open Networks; 
DRAGON 2004) cultural related problems during a collaborative product development process are addressed using collaborations between Chinese and European companies. One main objective of the project is to develop an internet-based service called Cultural Repository (CR). It aims to support enterprises to overcome barriers originating in different cultural backgrounds before and during the duration of a joint project. The business process as shown in Figure 1 is focus of this paper.

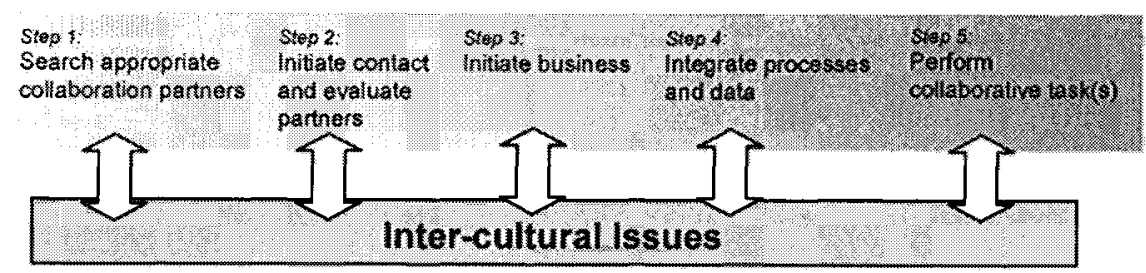

Figure I. The cultural influenced collaboration business process steps covered within the project

(Source: GRABOWSKI et al. 2003, p. 194)

\section{CULTURAL REPOSITORY (CR)}

The procedure of approaching the CR objectives consists of three phases; the first phase comprised the analysis of user's requested support, phase two and three are a conception and a realisation/evaluation phase.

\subsection{Results of Analysis Phase}

During an analysis phase structured interviews were conducted in order to analyse success factors for intercultural collaboration and requested support. The analysis and evaluation of interview results showed that the following requirements have to be considered when creating the CR:

1. Sensitisation is the basic need to make people aware of the fact that culture is a crucial factor for success or failure of international collaborations.

2. Provision of general information about the cultural background of a collaboration partner is another important functionality.

3. The service has the task to form a common platform facilitating cultural knowledge transfer and knowledge sharing among users. 
4. The analysis brought up the importance of personal relationships for the success of intercultural projects. Therefore the portal should facilitate the development and maintenance of personal networks.

5. The portal should also improve joint understanding of terms and processes among project partners in order to prevent misunderstandings leading to wrong expectations.

Moreover, the CR concept faces two main challenges that result from the basic characteristics of culture. The dynamic character of the culture leads to the first challenge. Though some characteristics of a culture may seem to remain the same over centuries, it should not be forgotten that culture is constantly changing. The other challenge is due to limitations to what can be achieved by means of an Internet portal when dealing with cultural issues. These limitations are partly due to the medium and partly due to the fact that cultural interactions take place between the human beings.

At this point, it can be ascertained that the CR cannot fully replace personal relationships between partners. Instead, it can help to determine what should be regarded as important in relationships and in which areas personal contact is indispensable.

\subsection{Results of Conception Phase}

Based on the results of the analysis phase, four functionalities of the $\mathrm{CR}$ were defined to meet the terms specified in the requirements:

1. Cultural Guidelines,

2. Cultural Data Base (Search \& Find Functionality),

3. Agent Functionality,

4. Knowledge Management (experience sharing).

Figure 2 briefly outlines the contents of the CR functionalities. Furthermore, this the figure shows that the functionalities have access to a Culture Database. This database is split into two parts: an Information Base and a Knowledge Base. All information which is provided by the CR is stored in these databases. The contents of each function is described in detail in the following sections.

Tablel displays the contribution of the functionalities to the fulfilment of the requirements, as described above. 


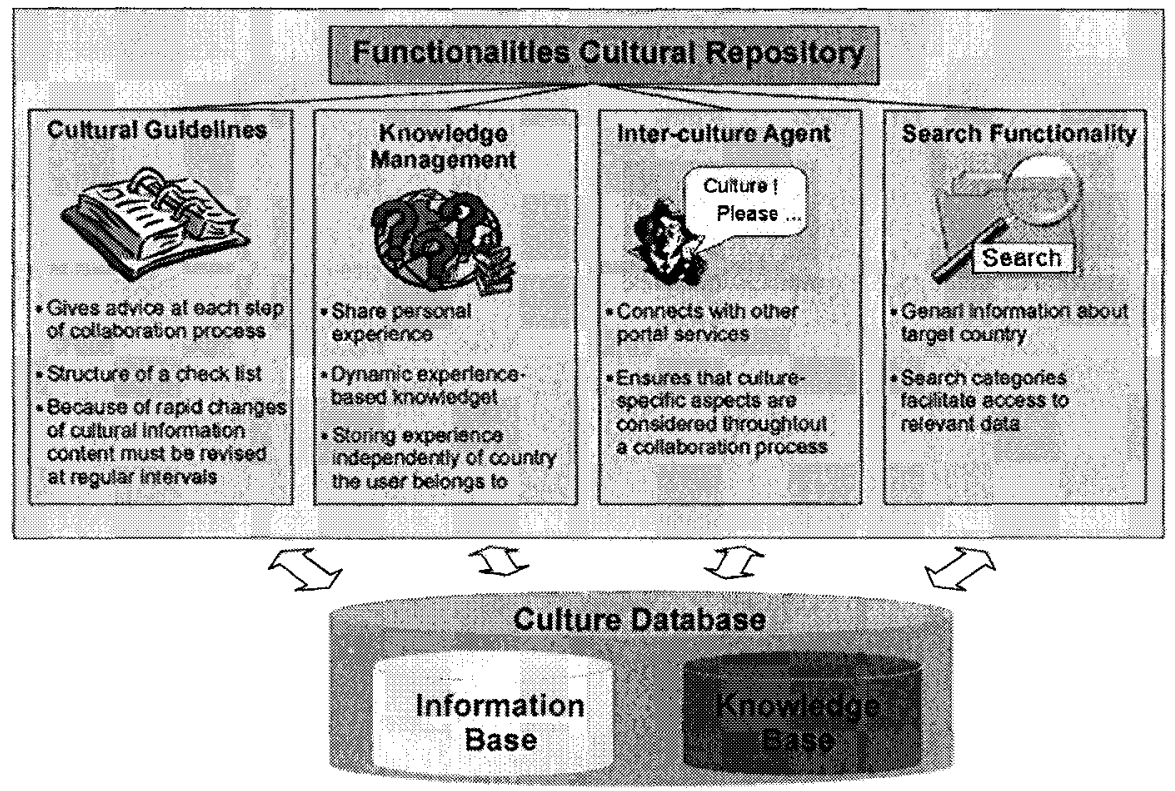

Figure 2. Functionalities of the cultural repository

Table 1. Contribution of $\mathrm{CR}$ functionalities to fulfil the predefined requirements

\begin{tabular}{lccccc}
\hline & Sensitation & $\begin{array}{l}\text { Provision of } \\
\text { general } \\
\text { information }\end{array}$ & $\begin{array}{l}\text { Knowledge } \\
\text { transfer }\end{array}$ & $\begin{array}{l}\text { Personal } \\
\text { relationship }\end{array}$ & $\begin{array}{l}\text { Joint understanding } \\
\text { of terms and proc- } \\
\text { esses }\end{array}$ \\
\hline $\begin{array}{l}\text { Cultural } \\
\text { Guidelines }\end{array}$ & {$[\mathrm{x}]$} & {$[\mathrm{x}]$} & & & {$[\mathrm{x}]$} \\
$\begin{array}{l}\text { Search \& } \\
\begin{array}{l}\text { Find Func- } \\
\text { tionality } \\
\text { Agent Func- }\end{array}\end{array}$ & {$[\mathrm{x}]$} & {$[\mathrm{x}]$} & {$[\mathrm{x}]$} & & \\
tionality & {$[\mathrm{x}]$} & {$[\mathrm{x}]$} & & & \\
$\begin{array}{l}\text { Knowledge } \\
\text { Management }\end{array}$ & {$[\mathrm{x}]$} & {$[\mathrm{x}]$} & {$[\mathrm{x}]$} & {$[\mathrm{x}]$} & \\
\hline
\end{tabular}

\subsubsection{Cultural Guidelines}

In order to sensitise companies which are involved in or intend to set-up an intercultural co-operation, the function Cultural Guidelines (CG) is being developed. The $\mathrm{CG}$ gives advice about what are the important cultural aspects and potential barriers to be considered for each step of a collabora- 
tion process. For example, before initiating business (see Figure 1) with a new co-operation partner, both sides of the partnership will go through a negotiation phase. When negotiating with a person from a different cultural background, certain rules of conduct should be followed in order to avoid misunderstandings or failure. Beyond sensitisation, the CG provides information how the encountered intercultural barrier can be overcome.

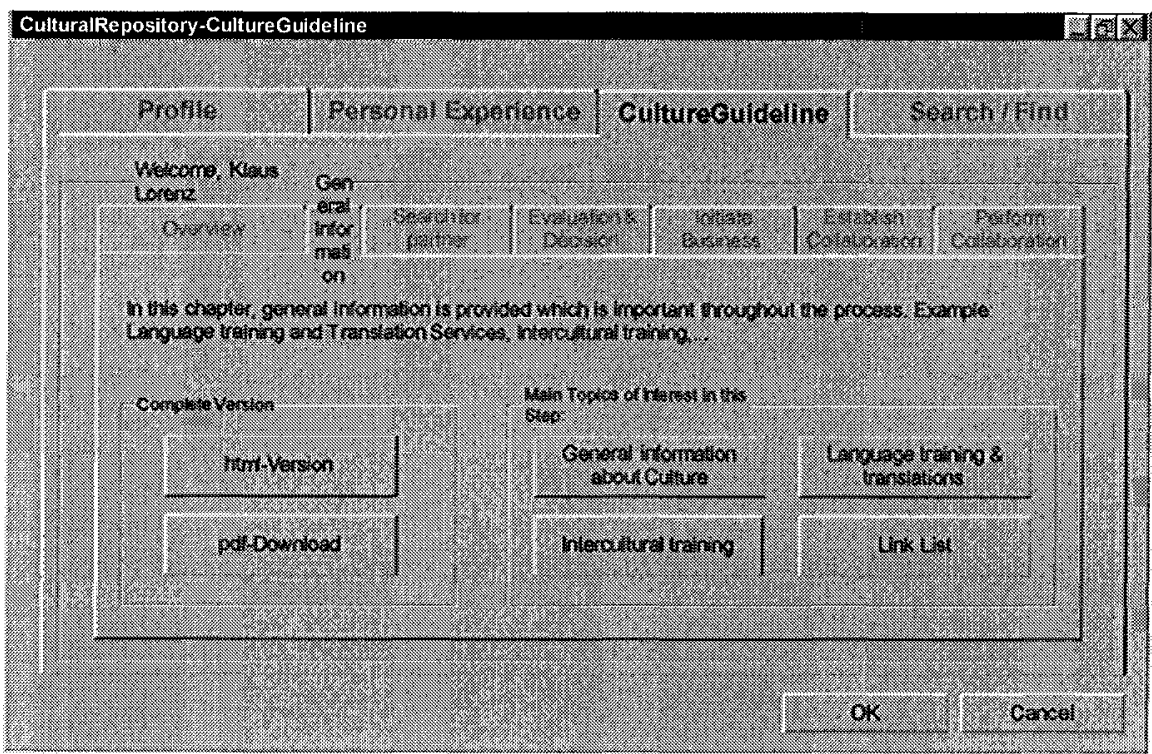

Figure 3. User interface of cultural guideline

The structure of the DRAGON collaboration business process is used to organise the information provided by the CG (see Figure 3). This set-up allows a targeted browsing as the user is able to navigate by following the chronological cycle of a co-operation. In addition, this structure enables the inexperienced user to learn about important cultural obstacles in a collaboration by simply following the co-operation business process. Whereas a user more experienced in collaborations can directly chose a business step relevant for him.

As cultures differ from nation to nation, the arising cultural barriers are different for each culture. Thus, for each culture guidelines will be provided. The information aggregated in the guidelines was collected during the analysis phase, and completed with current literature. Due to the rapid changes of cultural information, the content of this service must be revised at regular intervals. This function offers a comprehensive, process-accompanying collection of information which covers the complete collaboration process 
suited for a specific culture. It supports the co-operation partners to develop a common understanding for processes and terms.

\subsubsection{Search \& Find Functionality}

Mirrored on the requirements the main focus of the Search\&Find (SF) functionality is to provide general information about a target country. Beside cultural information like religion or cultural aspects, it also holds information about the geography, legal and political system, relevant business information for investments, etc. The information is stored in an underlying database.

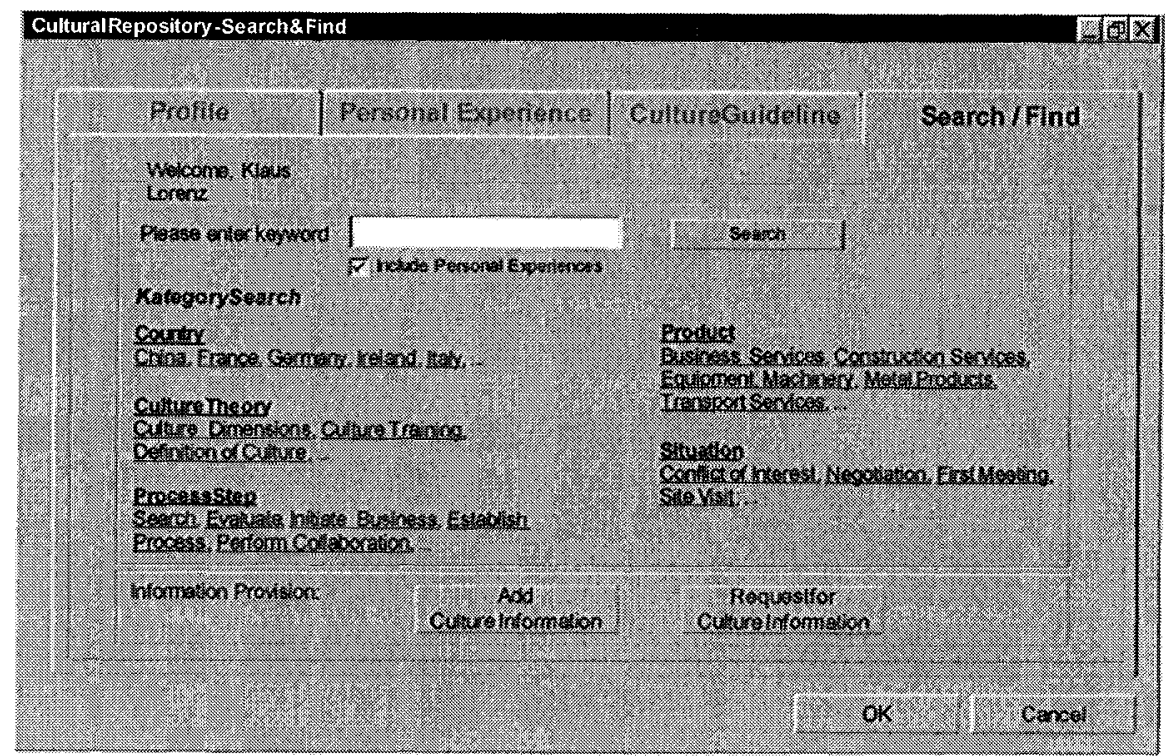

Figure 4. User interface of search \& find functionality

The user can directly access the database to request or enter information. In order to find desired information, the user can choose from given categories and/or enter key words (see Figure 4). As cultural information is subject to constant change, the data accessed via the SF functionality have to be regularly reviewed and updated. Compared to the $\mathrm{CG}$, this functionality provides more general information about a culture detached from the co-operation process. 


\subsubsection{Agent Functionality}

The Inter-culture Agent (IA) is intended to assist the user of the DRAGON-portal regarding cultural issues at crucial steps during the complete lifecycle of the DRAGON collaboration process.

Beside the CR, the DRAGON portal comprises other components like a Specification Modeller Component (SMC) or Request \& Navigation Component (RNC). These components support the user of the DRAGON-portal during the various steps of the collaboration process. Hence, the IA is triggered from components other than the $\mathrm{CR}$. The kind of assistance provided can vary depending on the current position in the lifecycle. In general, it functions as a reminder for the user to consider cultural issues and cultural influences for his collaborative work, thus sensitising the user for cultural aspects. It suggests references for cultural categories and topics to the user, which are relevant for the current process step. The IA retrieves the information sending a request to the database.

A more advanced alternative of the inter-culture agent could provide the user with more detailed and tailored information. Instead of the user searching the cultural database the agent retrieves the information sending a request to the database. For example, at certain steps the cultural peculiarity of a specific country or group can have a crucial impact on the proceedings of the DRAGON component SMC and therefore should be considered for the further planning, monitoring and control of the course of the process. The requirements for a product, which are defined in the SMC, can be influenced through culture. A washing machine designed for the Indian market does not need a $90^{\circ}$ washing program. Indian people mainly wear clothes made out of fabric, which should not be washed at that temperature. In this example the Agent functionality is activated when the user begins to define the requirements in the SMC. Then the Agent provides suited support for the specific step. The inter-culture agent will inform the user to consider cultural peculiarities when specifying the product requirements. If the user has already defined the target country and the product or product group the agent can provide the more specific information from the data base, i.e. that a washing machine in India does not need a $90^{\circ}$-washing program.

The user always decides whether to accept or not the support of the IA. The type of support given by the Agent depends on the triggering event of the current DRAGON-component, the available data in the cultural database and the degree of specification by the user.

The IA will only be triggered at specific occasions in order to avoid an overuse. 


\subsubsection{Knowledge Management}

The Knowledge Management (KM) functionality facilitates the management, exchange, and sharing of personal experiences gained during an intercultural collaboration process. Experience is valuable, stored, specific knowledge that was acquired in a problem solving situation (BERGMANN 2002). Thereby, experience is in contrast to general knowledge as provided in the CG and Search \& Find Functionality. Through the KM, enterprises are enabled to share and transfer the culture related experience of their employees in order to avoid mistakes caused by cultural differences in future product development processes. The KM supports the intention of the Cultural Repository to take into account the dynamic change of culture through updating experience and entering new experience into the database.

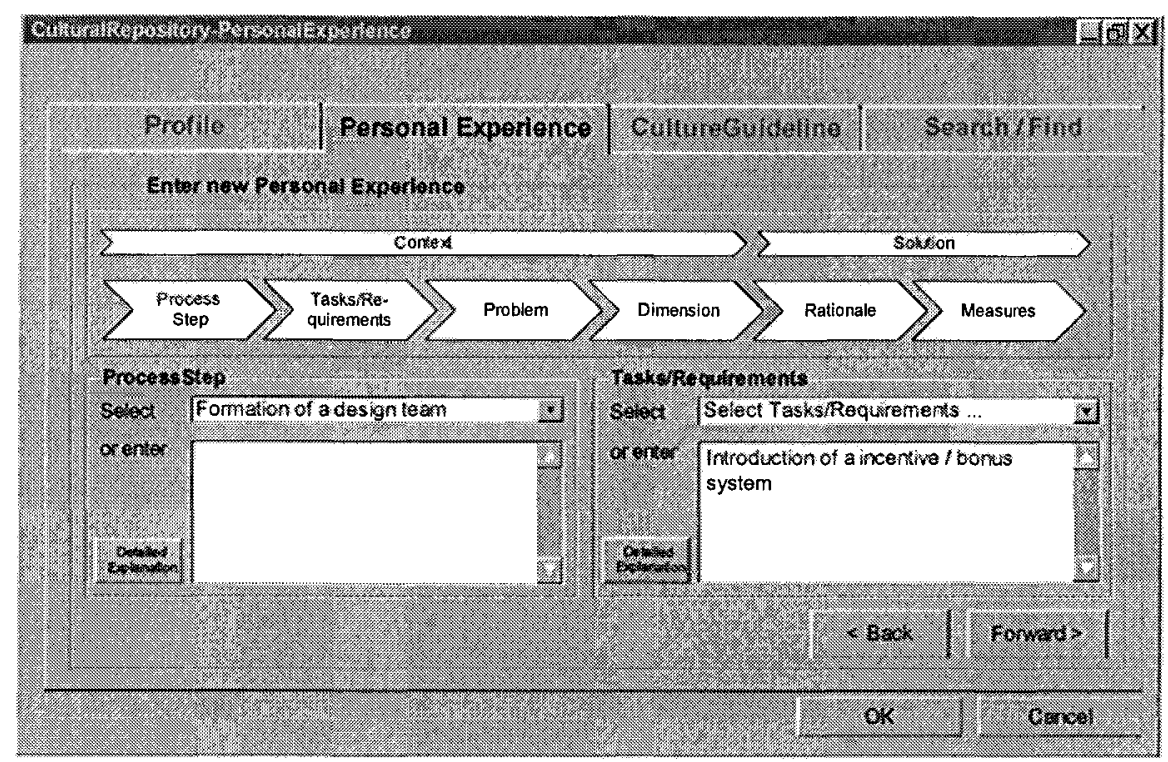

Figure 5. User interface of knowledge management

The method of solution patterns according to SUHM (1993) is used to store the experience of a user. A solution pattern consists of a context and a solution. The solution consists of a rationale and a measure. In the rationale it is described why the cultural problem occurred. The measure delivers methods how to overcome the problem. In order to be able to retrieve the solution from the knowledge base, the solution is allocated to a context. The context describes the situation in which the user collected his experience. It consists of the process step during which the cultural problem occurred, the 
description of the problem and the concerned part of culture where it occurred.

Using the structure of a collaboration process to classify the stored experience makes it possible to attribute experience to a relevant step of a collaboration process. This classification contributes to the purpose of the DRAGON portal to ensure a process-orientated support for enterprises during build up and process of a common collaboration and allows the user to find knowledge for a certain process step in the collaboration.

With the assistance of cultural dimensions (HOFSTEDE 2001) it becomes possible to assign the part of culture, which caused the problem and to store experiences independent of the country the user belongs to (see Figure 5). This approach enables the portal user to find a solution for a cultural caused problem for a certain process step in a collaboration. It informs about which part of a culture caused the problem.

\subsection{Realisation / Evaluation Phase}

\subsubsection{Data Sharing and Provision in a Distributed Work Environment}

The CR aims to support enterprises which are part of a cross-national cooperation, i.e. the users of the $\mathrm{CR}$ are part of a distributed work environment and can be spread over several countries. From there it is important to allow an access to the functionalities of the CR independent of time and place. Further the database of the CR can contain links and references to relevant information which is stored in variable distributed data sources, e.g. homepages on the Internet.

Internet Technology is employed to achieve both, an access to the CR independent of time and place and access of the CR to relevant information in distributed data sources. The CR is part of the DRAGON Engineering Portal and makes use of the data management and user administration capacities provided by the portal. The core of the portal is formed by an information platform called Data Information Broker (DIB). The DIB provides a transparent view on distributed data sources and contains fundamental functionalities to access the portal and to access and administer distributed data sources. Web services are used to link the CR to the DIB.

\subsubsection{Scope of realisation}

Within the scope of the DRAGON project, the focus for the realisation of the concept is laid upon the KM-, CG and CD-functionalities. At this point of time, the first prototypes are being developed. In parallel an evaluation 
phase will take place where the suitability of the Cultural Repository in dispersed intercultural engineering projects is assessed. Follow-up projects will be initiated in the near future in order to further advance the realisation of the concept.

\section{CONCLUSION}

Although there is an increasing awareness of the importance of intercultural differences, the practical implementation of these issues in international projects is often insufficient. The CR offers an approach on how intercultural aspects are integrated into a portal-based working environment for dispersed projects.

In order to fulfil the users' request for up-to-date information about the target country, the $\mathrm{CR}$ offers cultural guidelines and a culture database. Agent functionality interconnects the Cultural Repository with other DRAGON-components.

To meet the challenge that culture is constantly changing, CR creates a platform for knowledge transfer between project participants across cultural boundaries. Thus, it does not only refer to static information that becomes rapidly obsolete and worthless. The Knowledge Management component also takes into account that culture takes place between human beings by supporting the built up and maintenance of personal networks.

\section{ACKNOWLEDGEMENTS}

The results of the presented work were achieved with the valuable collaboration of Dr. Ralf Lossack from Institute for Applied Computer Science in Mechanical Engineering (RPK) of Karlsruhe University and Barbara Bumeder and Eva Dietz from Siemens AG, Corporate Technology, Munich.

\section{REFERENCES}

BERGMANN, Ralph:

Experience Management

Berlin: Springer Verlag, 2002.

DRAGON:

Development of an interactive Engineering Portal for Open Networks.

Karlsruhe: Institute for Applied Computer Science in Mechanical Engineering, 2003.

http://www.dragon.uni-karlsruhe.de, 05.04.2004. 
GRABOWSKI, Hans; LOSSACK, Ralf-Stefan; SANDER, Matthias; BUMEDER, Barbara; DIETZ, Eva:

Overcoming Cultural Barriers in Distributed Work Environments.

In: Human Aspects in Production Management.

Eds.: ZÜLCH, Gert; STOWASSER, Sascha; JAGDEV, Harinder S.

Aachen: Shaker Verlag, 2003, pp. 194-200.

(esim - European Series in Industrial Management, Volume 5)

HOFSTEDE, G.:

Culture's Consequences.

Beverly Hills: Sage, 2001.

SUHM, A.:

Produktmodellierung in wissensbasierten Konstruktionssystemen auf der Basis von Lösungsmustern.

Aachen: Shaker Verlag, 1993. 